importance to those concerned with mineral exploration, and the author had the needs of such people in the forefront of his mind when writing his book.

Perel'man has confined his attention solely to the geochemical aspects of epigenesis in the book under review, and consideration of the processes noted above makes it abundantly clear that such a work must be concerned primarily with the mobilization, migration and deposition of substances in the supergene zone. Virtually every facet of these topics is dealt with comprehensively and clearly, and although the author states that a complete understanding of the processes in question cannot be arrived at via the physico-chemical concepts of the laboratory worker because "natural reactions take place in conditions which are in most cases unknown to chemists", yet the relative importance of the various physicochemical controls is clearly revealed.

In the space available it is quite impossible to note the many novel and important items in the work, but biological migration, the abundance concept, the classification of epigenetic processes and geochemical barriers are among the most exciting.

The diagrams are generally clear, and they and the tables are distinctly useful. Only a few, comparatively unimportant, typographical errors mar the text.

The bibliography, containing 248 references, is not likely to be of great use to the average reader, as all but a few of the references relate to Russian works; nor does it truly reflect the valuable work carried out in the field by scientists outside Russia.

I highly recommend this book to geochemists, ore geologists, sedimentologists, pedologists and geomorphologists. K. F. G. Hosking

\section{HOW ROCKS DEFORM}

\section{Engineering Properties of Rocks}

By I. W. Farmer. Pp. 180. (Spon: London; Barnes and Noble: New York, 1968.) 36s.

A BASIC knowledge of the conditions under which rocks deform and their properties with respect to engineering problems is essential to the civil and mining engineer and the engineering geologist. It is also very useful to the structural geologist studying rock deformation, and hence although primarily written for the engineer the book has a dual audience.

The book deals with those properties of igneous, metamorphic and sedimentary rocks which pertain to enginecring and construction, investigates their nature showing how they may be measured in the field and in the laboratory, and suggests ways in which some of the problems posed by certain properties may be overcome.

After an introduction to the chemical and physical properties of rocks and their composition, the concepts of stress and strain are discussed in some detail from a theoretical point of view, and, in a later chapter, the mothods by which measurements of these properties may be made explained. The strain ellipsoid is given thorough treatment and this leads into a consideration of the elasticity and fluidity of rocks.

The precise procedures conducted in order to test a rock for stress, strain, creep shear, and the like, both in the laboratory and in the field, are described.

The static properties of stress, strain, elasticity and strength of rocks may vary, and in some cases are controlled by such factors as porosity and permeability, temperatures and pressure, depth of burial, which in turn are related to the structural environment in which the rocks are found. The situation is further complicated by the fact that these variables affect different rock types in different ways and what may be true for a sandstone is not true for a granite, much less a limestone. The treat- ment of this particular section would have benefited from a slightly more geological bias than is given and an actual case history with examples would have been appropriate.

Having thus far given an account of the properties of rocks under varying conditions, the author goes on to explain how they may bo put to use in designing structures which rocks will support.

Graphs and diagrams illustrate the text well and a useful bibliography is included. Whilst the mathematics in the book will present little difficulty to engineers, for whom the book was primarily written, geologists, never the best of mathematicians, will need to brush up their calculus. It is a pity in some ways that some aspects are not treated in a more petrological manner, but this would have meant a larger book. Also much of the mathematies is highly condensed and the non-specialist mathematician will have to take on trust some of the steps both implicit and explicit. Any scientist secking a basic introduction to the strength properties of rocks would, however, spend a long time looking for a more concise account. JoHN R. V. Brooks

\section{RADIOCHEMICAL ANALYSIS}

\section{Substoichiometry in Radiochemical Analysis}

By J. Ruzicka and J. Stary. Edited by M. Williams. (International Series of Monographs in Analytical Chemistry, Vol. 30.) Pp. ix +151 . (Pergamon Press: Oxford, London and New York, 1968.) 55s.

THIS slim volume gives a brief description of modern technique based mostly on radioactive assays, such as neutron activation analysis for the determination of traces of elements, analysis of radioactive materials, also isotope dilution techniques and some related methods. These techniques have been in use for a considerable time and have been dealt with previously in a number of textbooks and monographs. The justification for this publication might perhaps be seen in the fact that it gives some more detailed information about the work carried out particularly in the laboratory of the authors in the department of nuclear chemistry in the Technical University of Prague; also perhaps that it appears within a series of "Monographs in Analytical Chemistry". The book is well produced, with a number of tables and figures and 122 literature references, and could be recommended as an introduction to this field.

J. J. Weiss

\section{VIBRATING CRYSTALS}

\section{The Anharmonic Crystal}

By Philippe Choquard. (Frontiers in Physics : a Lecture Note and Reprint Series.) Pp. xii +340 . (Benjamin: New York and Amsterdam, 1967.) \$10 cloth; $\$ 5.95$ paperback.

THE problem of handling the anharmonic properties of crystals has exercised physicists for more than forty years. The earliest systematic attempts followed Born's massive work on lattice dynamics. Born and Brody (1921) and Schrödinger (1922) both showed that at high temperatures cxtra terms in the heat capacity arc obtained, both in a classical and in a quantum formulation. To a first approximation these are proportional to temperature.

Further work, which relied mainly on a Grüneisen approach, has not materially altered the situation, except that in the one-dimensional chain an exact solution was obtained for all the high temperature properties.

It has always been clear that a systematic extension of the Born-Brody approach would lead to a power series in 